\title{
Research on Adjustment of Industrial Structure and Development of Higher Vocational Specialties
}

\author{
Delin Chen \\ Xianning Vocational Technical College, Xianning, 437100, China
}

Keywords: industrial structure; higher vocational colleges; higher vocational specialties

\begin{abstract}
The target nature of the talent training of higher vocational colleges determines the specialties setup of higher vocational colleges. The adjustment of industrial structure provides a good opportunity for the connotation construction of higher vocational education. This paper analyzes the current situation of specialties construction in higher vocational colleges under the background of industrial structure adjustment, and puts forward some corresponding countermeasures, including promoting autonomy of specialties setup of higher vocational colleges, strengthening practical training of specialties setup and avoiding convergence of specialties setup to provide some references for the relevant researchers.
\end{abstract}

\section{Introduction}

Specialties construction is the core carrier for the vocational colleges to play the training function of skilled talents and serve the economic and social development [1]. To a great extent, the function of this function depends on whether the professional structure of the higher vocational college adapts to the change of industrial structure. China will speed up the transformation of the economic development mode and achieve the goal of upgrading and optimizing the industrial structure. Every region will intensify efforts to transform traditional industries, vigorously develop technology intensive high-tech industries, and local industrial structure will usher in a period of readjustment. Therefore, adapting to the adjustment and change of local industrial structure, optimizing the professional structure and improving the ability of serving the local economic and social development is a major task faced by our vocational colleges. The development of higher vocational education is inseparable from the support of regional economy for all aspects, such as the input of educational funds, the construction of school enterprise cooperation base, and the employment of students. In order to promote the development of economy, the industrial structure needs continuous optimization and upgrading. The upgrading and upgrading of industrial structure will inevitably require higher vocational colleges to adjust their professional structure to match them, so that higher vocational education can survive and develop. Therefore, when a certain industry is in the dominant position in the regional economy, the number of corresponding higher vocational professional settings should be increased. On the other hand, when the proportion of a certain industry in the area of regional GDP falls, the number of corresponding professional professional settings should be reduced accordingly. The main goal of higher vocational education is to cultivate high-quality and skilled talents for local economic construction and social development. The success of higher vocational education is subject to the rationalization of its professional structure. There is no doubt that a reasonable professional structure will promote the optimization and upgrading of the regional industrial structure, and then promote the development of the regional economy. Otherwise, the employment of talents trained in higher vocational education will be difficult, which will not only cause waste of resources in higher vocational education, but also cause structural shortages of talents needed for upgrading regional industrial structure [2]. 


\section{Current Situation of Specialties Construction of Higher Vocational Colleges under the Background of Industrial Structure Adjustment}

\subsection{Improper administrative intervention}

Higher vocational education reform achievements, however the resistance is very serious, the main manifestations are: the plan of instruction still exists, independent recruitment policy is not well implemented in higher vocational colleges; the lack of effective means of macro-control, public services caused by inadequate policy implementation; without the establishment and development of the provincial education occupation and service platform in Specialized Committee occupation education for enterprise and industry, the alienation of school and enterprise, industry, set up a new professional not to strict market research and scientific analysis as the basis, only pay attention to their own interests. Such as: do not attach importance to the large social demand but need high investment, low economic efficiency of the major. The industry with a certain market demand and traditional advantages, including paper making, steel, shipbuilding and so on, is very limited to its corresponding professional setting. On the other hand, on the other hand, the shortage of short line specialties in large-scale recruitment has been ignored in the neglect of market demand. According to the government to adjust industry planning, reasonable development of local higher vocational colleges professional structure planning scheme, specialized reorganization to the rational allocation of resources in higher vocational education, adhere to the "application, prospective, innovation and efficiency" principle, according to the needs of local economic development, the creation of new professional, who cannot adapt to the needs of the old industry out of professional transformation the traditional professional training of skilled talents, a number of high-tech industrial areas. Through the regulation and control of the enrollment plan, we can control the scale of the specialty, limit the number of enrollment, optimize the professional setting and control the professional structure. According to the local economic structure, the main major of the industrial structure, the regional pillar industry and the direction of development is set up. We should optimize the structure of Higher Vocational Education in order to adapt to the different needs of pillar industries, traditional industries and emerging industries [3].

\subsection{Overlooked market factors}

Higher vocational colleges blindly set professional, first is because of the neglect of market factors, the market prospect of strategic economic area including its own conditions, industrial policy and labor, the analysis is not enough, the target of professional construction and personnel training is not clear, lack of long-term effective planning, training a large number of professionals do not pile up in excess of requirement. Some of the market in urgent need of talent training system into the plan, resulting in the labor market supply and demand imbalance phenomenon of talent structure. Secondly, because higher vocational colleges are generally influenced by the idea of "small and whole", they only focus on expanding their scale to get short-term benefits while ignoring specialty and brand building, resulting in many professional duplication and waste of resources. Higher vocational schools should not only serve the local economic development, provide high skilled personnel for the social and industrial enterprises, but also consider the benefits of their own schools. Professional setting is closely related to the cost of running schools. When setting up majors, we need to clear up the demand and supply of professional talents through market research, and determine the scale of majors. In determining the professional setting, but also will share the same professional group construction in higher share, correlation in professional resources, the professional development of reasonable structure, appropriate scale, benefit significantly, strive to minimize the investment and optimize the allocation of resources, maximize the production, develop the best talent. The establishment of central specialty is not to abandon the original teaching characteristics and ideas, but to optimize the educational type and enrich its content. But what should be known is that the number of central specialties is best suitable, while the range between professional and professional is not too 
wide [4].

\subsection{Convergent specialties setup}

Professional industry not only to analyze the local industrial structure adjustment and economic development may accelerate the change, but also analyzes the opening area of other specialty in higher vocational colleges, to understand the other higher vocational colleges in the same area, the students, educational resources, graduate employment, personnel training and other aspects of the quality of the competition. This competition often have adverse effects on both sides, therefore, higher vocational colleges of the same area, professional settings should not disregard the dislocation development, teachers and teaching equipment and training conditions, arbitrarily set professional, professional settings to avoid blindness, similarity, promiscuity, so as not to affect the social reputation of the schools, the sustained and healthy development. Higher vocational education is highly skilled personnel. This kind of talent has a more direct and closer relationship with industry, enterprise, technology and profession in the region. Due to the influence of the change in the region and the use of the people's market, the specialty offered by higher vocational colleges should have a strong professional orientation. Taking Tangshan as an example, with the adjustment of industrial structure, new strategic support is needed for new energy vehicles, energy saving, environmental protection, high-end equipment manufacturing, biomedicine, electronic information and other strategic emerging industries. Therefore, the major setting of higher vocational education should be guided by the market and based on the change of regional industrial structure and the needs of social talents, and adapt to the transformation of social needs and professional positions through professional adjustment. Reform the professional training target system and establish the curriculum. The training goal of higher vocational education is the main basis of the curriculum. At present, the training target of higher vocational education should have all aspects of ability. The goal of training talents reflects the demand of professional technology, and the demand of vocational technology is the basis and starting point to determine the goal that the curriculum of higher vocational colleges should reach.

\section{Specialties Construction Strategies of Higher Vocational Colleges under the Background of Industrial Structure Adjustment}

\subsection{Promote autonomy of specialties setup of higher vocational colleges}

Due to the lack of overall design planning and argumentation and other related institutional arrangements, higher vocational colleges are blinded in their professional expansion, and they are not closely linked with industry, enterprises and professionals. The degree of marketization is not high, and the goal orientation of specialty construction and personnel training is vague. The higher vocational colleges are not enough to analyze the regional economic development strategy, including the industrial policy, the labor market prospect and its own conditions, and lack the long-term consideration. On the one hand, the oversupply of professional talents is still being trained in large numbers, resulting in difficulties in obtaining employment for graduates, but the badly needed talents are not satisfied, causing the structural shortage of labor market. To build the self-protection mechanism of the professional setting of colleges and universities. There are obvious differences in resource endowments between different regions in China. The development goals of different regions are not the same. Higher vocational colleges need to adjust measures to local conditions when meeting the needs of local industrial development. Therefore, in the professional setting, higher vocational colleges need to have greater autonomy. With the deepening of the reform of the management system of higher education in China, the higher vocational education has been managed by the provincial government. The Ministry of Education announced to seek advice from various colleges and universities. The draft proposed major in higher vocational colleges according to the management authority is divided into the professional and nonprofessional in control, professional control set, by the provincial administrative department of education examination, verification and 
approval of the Ministry of education in conjunction with the relevant competent departments of the state sector; non state controlled professional setting, by the provincial administrative departments of education and management. This indicates that the autonomy of professional institutions in higher vocational colleges will be greatly enhanced. At present, the Ministry of education should improve the revision of the draft and promulgate it as soon as possible. At the same time, the provincial government education authorities should introduce the management method of the major setting in higher vocational colleges as soon as possible, really give the autonomy of higher vocational colleges, and enhance the flexibility of the school to cope with the changes in industrial structure, and constantly optimize the professional structure.

\subsection{Strengthen practical training of specialties setup}

The classification of the social profession and the demonstration of the demand for talents are the important basis for the professional setting. Whether it is a new professional or a major that has been set up, it is necessary to carry out market research and write the analysis report of market analysis and professional setting. The training goal of higher vocational education is the main basis of the curriculum. The goal of training talents reflects the demand of professional technology, and the demand of vocational technology is the basis and starting point to determine the goal that the curriculum of higher vocational colleges should reach. Strengthen the construction of practice and training base, and improve the students' ability to do it. The characteristic of higher vocational education is now on the practical ability. The construction of practice and training bases is the key to enhance the ability of practice. It is also an important place for the combination of production and education and the training of skills. Should be based on the teaching plan as the basis, establish and adapt to the field production or production technology development level in recent century. The higher vocational education pays attention to the training of the students' hands-on ability, and requires the teaching content to highlight the practical teaching. The combination of production, teaching and research is a teaching mode that aims to cultivate applicable talents who are suitable for Industry and business needs. The enterprises and schools to their respective advantages, realize the combination of theory and practice, on the one hand, the school provides the technical support for the enterprise, on the other hand, the practice of enterprises to provide places for the school, the students through the cooperation with enterprises, will use the knowledge to production and Engineering practice. Through professional advantages, we organize teachers and students to apply technology development and research, participate in economic activities of enterprises.

\subsection{Avoid convergence of specialties setup}

The early warning mechanism for the construction of higher vocational education includes three levels: the national level, the provincial level and the school level. The professional construction of early warning mechanisms at the national level the main structure and regulation of the students enrollment professional national unemployment rate and unemployment was highest in the most professional and professional class; provincial professional construction of early warning mechanism is in the implementation of the national macro-control, the local higher vocational education and the labor market supply and demand characteristic of the early warning and control. Due to the different development of key industries in all regions, the talent demand differences, and vocational training is mainly for the local industrial development needs, therefore, the provincial professional construction of early warning mechanism is necessary; the early warning mechanism of university specialty construction to the school for half a year after graduation students annual employment status survey on employment rate for two consecutive years ranked in the school to the professional professional finally issued a warning, to reduce the enrollment plan, professional restructuring and transformation. The caliber of specialty setting is gradually formed, first and then narrow, to enhance professional awareness, and to set flexible professional direction or elective course group according to market demand, enhance professional adaptability and vitality, but avoid professional convergence and professional orientation convergence. Professional space should be given to students to choose more professional opportunities. The establishment should be based on the current situation and trend of 
local economic development, and in-depth demonstration of industrial evolution and talent demand.

\section{Conclusion}

The adjustment and optimization of professional structure of higher vocational colleges is closely related to the adjustment of industrial structure. Higher vocational colleges should pay close attention to the reform of the industrial structure policies in order to perfect and optimize the professional structure in terms of management system, especially at the executive level. Only in this way, the higher vocational education will have a broader prospects for development, and the higher vocational graduates have a more unimpeded career path.

\section{Acknowledgement}

The paper is 2017 key issues of Hubei educational science planning, "industrial structure adjustment and Research on professional construction and development of Higher Vocational Education” (2017GAO080) stage results.

\section{References}

[1] Wang Ying, Ni Chao. The Correlative Study of China's Industrial Structure and University Students Employment: An Empirical Perspective [J]. Journal of National Academy of Education Administration, 2014(6): 79-84.

[2] Dai Shaoqing, MengWeiyang. Research on the Coordinated Development of Industrial Structure and Specialty Structure in Jiaxing [J]. Reformation \& Strategy, 2015, 31(4): 127-130+137.

[3] Lin Zhuoling, Nie Ruihua, Liang Jianying. Degree of Coordination between Guangdong Universities' Basic Research Input and the Upgrading of Industrial Structure [J]. 2015, 28(6): 74-78.

[4] Shen Lujuan. Analysis on Adaptability between Industrial Structure and Specialty Structure in Higher Vocational Education under Background of Supply-side Reform - The Case of Zhejiang Province [J]. 2017, 38(17): 25-30. 